\title{
PRODUÇÃO DE CAPIM ELEFANTE UTILIZANDO PERCOLADO DE ATERRO SANITÁRIO
}

\author{
PRODUCTION OF ELEPHANT GRASS USING LEACHATE LANDFILL
}

\section{Daniela Costa Leite COELHOㅜㄹ Rafael Oliveira BATISTA ${ }^{2}$; Paulo Cesar Moura da SILVA ${ }^{3}$; Francisco de Oliveira MESQUITA}

1. Mestre, Doutoranda do Programa de Pós-Graduação em Manejo de Solo e Água, Departamento de Ciências Ambientais e Tecnológicas, Universidade Federal Rural do Semi-Árido - UFERSA, Mossoró, RN, Brasil. danielacleite@ yahoo.com.br; 2. Professor, Doutor, Departamento de Ciências Ambientais e Tecnológicas, Universidade Federal Rural do Semi-Árido - UFERSA, Mossoró, RN, Brasil; 3. Professor, Doutor, Adjunto do Departamento de Ciências Ambientais e Tecnológicas, Universidade Federal Rural do SemiÁrido, UFERSA, Mossoró, RN, Brasil. 4. Mestre e Doutorando em manejo de Solo e Água, PPGMSA/UFERSA, RN.

RESUMO: O uso do percolado de aterro sanitário (PAS) na produção de biomassa para fins energéticos é uma alternativa que minimiza a degradação ambiental. O presente trabalho objetivou analisar o efeito de distintas doses de PAS na produção de capim elefante (Pennisetum purpureum Schum.). Para isso, montou-se o experimento no delineamento em blocos casualizados, com cinco tratamentos (T1 - somente água de abastecimento - AA; T2 - 1mm dia ${ }^{-1}$ de PAS mais AA; T3 - 2mm dia ${ }^{-1}$ de PAS mais AA; T4 - 3mm dia ${ }^{-1}$ de PAS mais AA; e T5 - 4mm dia ${ }^{-1}$ de PAS mais AA) e cinco repetições, totalizando 25 parcelas experimentais. O capim elefante foi cultivado em ARGISSOLO VERMELHO - AMARELO Eutrófico, durante 132 dias em Mossoró/RN. Ao final do ciclo do capim elefante foram determinadas as características vegetativas altura de planta (AP), massa úmida da planta (MUP) e da folha (MUF) e massa seca das folhas (MSF). Comprovou-se para MUP, MUF e MSF que não houve diferença estatística entre os tratamentos, entretanto, para AP, o tratamento $\mathrm{T}_{2}$ apresentou maior valor $(2,86 \mathrm{~m})$, diferindo estatisticamente dos tratamentos $\mathrm{T} 4$ e T5. Em geral, o tratamento T2 apresentou melhor desempenho com relação às características vegetativas do capim elefante.

PALAVRAS-CHAVE: Lixiviado. Fertirrigação. Biomassa.

\section{INTRODUÇÃO}

A produção de biomassa na superfície das células dos aterros sanitários, a partir da aplicação de percolado como fonte de água e de nutrientes na produção de gramíneas, pode se tornar uma alternativa tecnológica de reuso (MATOS et al., 2008; SILVA et al., 2010).

Esta prática de reuso minimiza os efeitos erosivos no topo e nos taludes das células dos aterros sanitários, possibilitando a geração de matéria prima para fins energéticos, substituindo a madeira retirada, e minimiza, ainda, os impactos ambientais negativos da disposição inadequada do percolado de aterro sanitário no sistema solo-plantaatmosfera (SILVA et al., 2011; MATOS et al., 2013).

A disposição dos resíduos sólidos urbanos em aterros sanitários é uma prática adotada no território brasileiro, em função dos custos reduzidos e da disponibilidade de áreas para sua implantação (ALSAMAWI et al., 2009; CASTILHOS JUNIOR et al., 2010).

Mesmo aterrado, os resíduos sólidos urbanos geram um líquido de coloração escura, altamente poluidor, denominado percolado, resultante da degradação e solubilização do material orgânico dos resíduos sólidos urbanos, com a água infiltrada no aterro (MATOS et al., 2008; SANTOS; GONÇALVES-DIAS, 2012).

$\mathrm{O}$ percolado proveniente de aterros sanitários apresenta alta variabilidade composicional, destacando-se a presença de nutrientes importantes para a agricultura, como o nitrogênio, fósforo, potássio, alguns micronutrientes, além de matéria orgânica (MATOS et al., 2013), atribuindo-lhe elevado potencial para aproveitamento agrícola.

Segundo Carvalho et al. (2006), no Brasil quando o tratamento do percolado é realizado in situ, frequentemente se utilizam lagoas de estabilização, sistemas que requerem grandes áreas, muitas vezes pouco disponíveis em grandes centros urbanos.

Além disso, a eficiência relativamente baixa do sistema convencional de tratamento (lagoas anaeróbia seguida de facultativas) tem levado técnicos e pesquisadores a procurarem alternativas técnicas que possibilitem o tratamento $\mathrm{e}$ ou, disposição final do percolado com menor custo econômico e ambiental (CARVALHO et al., 2006).

Um método sustentável para disposição e tratamento do percolado de aterro sanitário é utilizálo como fonte de nutriente e água no solo, aplicando-o na forma de fertirrigação nas culturas mais acessíveis; cuja técnica se baseia no 
aproveitamento dos nutrientes presentes no resíduo líquido aplicado sobre as áreas cultivadas, utilizando-se, ainda, em conjunto, práticas de manejo agronomicamente adequadas para resolver os problemas de qualidade ambiental (SILVA et al., 2011; MATOS et al., 2013).

Segundo Santos (2011), o capim elefante (Pennisetum purpureum Schum.) é muito conhecido e utilizado como forragem na alimentação de animais, mas o seu uso como biomassa energética é pouco conhecido. Esta planta apresenta o colmo como uma parte fibrosa, mais dura, que forma a casca e uma medula com feixes vasculares, produzindo no Brasil em média 40 toneladas de biomassa seca por hectare, o que corresponde ao dobro da biomassa produzida pelo eucalipto.

O capim elefante apresenta vantagens em relação às demais fontes de biomassa, tais como a maior produtividade, o menor ciclo produtivo (6 meses), o melhor fluxo de caixa e a possibilidade de mecanização total do cultivo. As aplicações energéticas atuais desta gramínea são a combustão direta, a gaseificação, o carvoejamento e a hidrólise do bagaço (SANTOS, 2011).

Uma das formas de se manter o aproveitamento dos resíduos constituintes da biomassa vegetal é por meio do processo de briquetagem (formação de briquetes), onde resíduos lignocelulósicos, como serragem maravalha, casca de arroz, palha de milho, sabugo, bagaço de canade-açúcar e até mesmo resíduos de capim elefante são importantes no processo de compactação servindo de matéria-prima na substituição da lenha e carvão por um produto equivalente (SCHÜTZ et al., 2010; RAMOS; PAULA et al., 2011).

Apesar do percolado de aterro sanitário possuir potencialidade de uso na agricultura, existe pouca informação referente a seus efeitos sobre as plantas. Portanto, torna-se evidente a importância de estudos concernentes aos efeitos, decorrentes da disposição do percolado de aterro sanitário, no ambiente e nas plantas, na tentativa de viabilizar tecnologias alternativas para seu tratamento/disposição final (MATOS et al., 2013).

Neste contexto, objetivou-se neste trabalho, analisar o efeito da aplicação de cinco doses de percolado de aterro sanitário na produção de capim elefante, para fins energéticos.

\section{MATERIAL E MÉTODOS}

Este trabalho foi realizado na Unidade Experimental de Reuso de Água (UERA) da Universidade Federal Rural do Semi-Árido (UFERSA) em Mossoró/RN sob as coordenadas geográficas $5^{\circ} 11^{\prime} 31^{\prime}$ 'de latitude sul e $37^{\circ} 20^{\prime} 40^{\prime}$ ' de longitude oeste e altitude de $18 \mathrm{~m}$.

O clima da região, segundo a classificação de Köppen, é do tipo BSwh' ("clima seco, muito quente e com estação chuvosa no verão atrasando-se para o outono"), com precipitação pluviométrica bastante irregular, com média anual de $673,9 \mathrm{~mm}$; temperatura média de $27^{\circ} \mathrm{C}$ e umidade relativa do ar média de 68,9\% (CARMO FILHO; OLIVEIRA, 1995).

O solo da área experimental foi classificado como ARGISSOLO VERMELHO-AMARELO Eutrófico (EMBRAPA, 2006), tendo camada impermeável a partir da profundidade de $0,4 \mathrm{~m}$. Apresentam-se nas Tabelas 1 e 2 as características físicas e químicas do solo da área experimental, antes da aplicação do percolado de aterro sanitário, determinadas pela metodologia da EMBRAPA (SILVA, 2009).

Tabela 1. Características físicas iniciais do solo utilizado no experimento.

\begin{tabular}{|c|c|c|c|c|c|c|}
\hline Profundidade & Densidade do solo & Areia & Silte & Argila & \multicolumn{2}{|c|}{ Umidade (\%) } \\
\hline$(\mathrm{m})$ & $\mathrm{g} \mathrm{cm}-3$ & & $\mathrm{~kg} \mathrm{~kg}^{-}$ & & $0,01 \mathrm{MPa}$ & $1,5 \mathrm{MPa}$ \\
\hline 0 a 0,20 & 1,61 & 0,86 & 0,1 & 0,05 & 11,43 & 3,67 \\
\hline 0,20 a 0,40 & 1,65 & 0,71 & 0,07 & 0,23 & 21,47 & 14,17 \\
\hline
\end{tabular}

Tabela 2. Características químicas iniciais do solo utilizado no experimento.

\begin{tabular}{|c|c|c|c|c|c|c|c|c|c|c|c|c|c|c|c|c|c|}
\hline Prof. & pH & $\begin{array}{c}\text { CE } \\
d S m^{-}\end{array}$ & $\begin{array}{c}\text { MO } \\
\text { dag }^{-} \mathbf{g}^{-}\end{array}$ & $\mathbf{N}$ & & $\mathbf{K}^{+}$ & $\mathrm{Na}^{+}$ & $\mathbf{C a}^{2+}$ & $\mathbf{M g}^{2+}$ & $\mathbf{A l}^{3+}$ & $\begin{array}{r}\mathrm{H}+\mathrm{Al} \\
\mathrm{cmol}\end{array}$ & $\begin{array}{l}\text { SB } \\
\mathrm{Im}^{-}\end{array}$ & $\begin{array}{c}\text { CT } \\
\text { C }\end{array}$ & 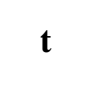 & $\mathbf{V}$ & M & PST \\
\hline (m) & & 1 & 1 & $\mathrm{~g} \mathrm{~kg}^{-1}$ & ............. & $\mathbf{n g ~ d m ^ { - 3 }}$ & ....... & $\ldots \ldots$ & & . . & & & & & & & \\
\hline $0,0-0,20$ & 6,6 & 0,12 & 0,68 & 0,54 & 328,24 & 104,45 & 13,64 & 2,09 & 0,79 & 0 & 0,28 & 3,21 & 3,49 & 3,21 & 92,67 & 0 & 1,77 \\
\hline $0,20-0,40$ & 6,6 & 0,13 & 0,57 & 0,62 & 275,48 & 121,88 & 9,28 & 2,46 & 1,17 & 0 & 0,3 & 3,98 & 4,28 & 3,98 & 93,95 & 0 & 0,9 \\
\hline $\begin{array}{c}\text { Prof. } \\
\text { (m) }\end{array}$ & & $\mathrm{Fe}$ & M & & C & u & $\ldots \ldots \ldots$ & mg & & $\mathbf{N i}$ & & & $\mathbf{P b}$ & & & Cd & \\
\hline
\end{tabular}




\begin{tabular}{cccccccc}
\hline $0,0-0,20$ & 97,58 & 88,21 & 0,52 & 6,13 & 0,07 & 0,27 & 0,01 \\
$0,20-0,40$ & 126,72 & 90,56 & 0,46 & 3,77 & 0,13 & 0,29 & 0,01 \\
\hline
\end{tabular}

pH - Potencial hidrogeniônico; CE - condutividade elétrica; M.O - matéria orgânica; SB - Soma de bases; CTC - Capacidade de troca de cátion; $\mathrm{t}$ - capacidade de troca de cátions efetiva; V - saturação por bases; $\mathrm{m}$ - saturação por alumínio; PST - porcentagem de sódio trocável.

Os ensaios experimentais ocorreram no período de abril a agosto de 2012, para isso transportou-se o percolado do aterro sanitário do município para a UERA/UFERSA em recipiente plástico com capacidade armazenadora para 1000L. Enquanto, a água de abastecimento utilizada no trabalho foi oriunda da rede pública da Companhia de Águas e Esgotos do Rio Grande do Norte (CAERN).
As características físico-químicas e microbiológicas do percolado de aterro sanitário e da água da rede de abastecimento foram determinadas mensalmente no período de maio a agosto de 2012, seguindo as recomendações do Standard Methods for the Examination of Water and Wastewater (RICE et al., 2012), conforme apresentado na Tabela 3.

Tabela 3. Características físico-químicas e microbiológicas da água de abastecimento (AA) e do percolado de aterro sanitário (PAS), ao longo do período experimental.

\begin{tabular}{|c|c|c|c|c|c|c|c|c|}
\hline \multirow[b]{2}{*}{ Características\Líquidos } & \multicolumn{2}{|c|}{$\begin{array}{c}\text { Amostragem de } \\
01 \text { de maio de } \\
2012 \\
\end{array}$} & \multicolumn{2}{|c|}{$\begin{array}{c}\text { Amostragem de } \\
01 \text { de junho de } \\
2012\end{array}$} & \multicolumn{2}{|c|}{$\begin{array}{c}\text { Amostragem de } \\
01 \text { de julho de } \\
2012\end{array}$} & \multicolumn{2}{|c|}{$\begin{array}{c}\text { Amostragem de } \\
01 \text { de agosto de } \\
2012\end{array}$} \\
\hline & $\mathbf{A A}$ & PRSU & $\mathbf{A A}$ & PRSU & $\mathbf{A A}$ & PRSU & $\mathbf{A A}$ & PRSU \\
\hline $\mathrm{pH}$ & 7,69 & 7,95 & 7,66 & 7,20 & 7,59 & 6,95 & 6,94 & 7,69 \\
\hline $\mathrm{CE}\left(\mathrm{dS} \mathrm{m} \mathrm{m}^{-1}\right)$ & 0,49 & 16,05 & 0,52 & 18,01 & 1,09 & 14,20 & 0,94 & 17,34 \\
\hline CTe (NMP $100 \mathrm{~mL}^{-1}$ ) & - & 0,0 & - & 0,0 & - & 0,0 & - & 0,0 \\
\hline $\mathrm{N}_{\text {total }}\left(\mathrm{mg} \mathrm{L}^{-1}\right)$ & - & 520 & - & 637 & - & 621 & - & 590 \\
\hline $\mathrm{P}_{\text {total }} \mathrm{l}\left(\mathrm{mg} \mathrm{L}^{-1}\right)$ & - & 7,1 & - & 3,0 & - & 5,0 & - & 4,5 \\
\hline $\mathrm{Fe}\left(\mathrm{mg} \mathrm{L}^{-1}\right)$ & 0,284 & 4,430 & 0,275 & 5,360 & 0,257 & 4,440 & 0,243 & 6,060 \\
\hline $\operatorname{Mn}\left(\mathrm{mg} \mathrm{L}^{-1}\right)$ & 0,008 & 0,090 & 0,007 & 0,660 & 0,017 & 0,020 & 0,005 & 13,850 \\
\hline $\mathrm{Cu}\left(\mathrm{mg} \mathrm{L}^{-1}\right)$ & 0,026 & 0,120 & 0,002 & 0,020 & 0,003 & 0,010 & 0,015 & 0,250 \\
\hline $\mathrm{Zn}\left(\mathrm{mg} \mathrm{L}^{-1}\right)$ & 0,048 & 2,450 & 0,051 & 0,647 & 0,054 & 0,718 & 0,053 & 0,708 \\
\hline $\mathrm{Pb}\left(\mathrm{mg} \mathrm{L}^{-1}\right)$ & 0,186 & 1,650 & 0,297 & 2,798 & 0,169 & 4,232 & 0,090 & 2,542 \\
\hline $\mathrm{Ni}\left(\mathrm{mg} \mathrm{L}^{-1}\right)$ & 0,089 & 1,520 & 0,140 & 2,378 & 0,141 & 1,468 & 0,101 & 2,936 \\
\hline $\mathrm{Cd}\left(\mathrm{mg} \mathrm{L}^{-1}\right)$ & 0,005 & 0,060 & 0,002 & 0,242 & 0,003 & 0,186 & 0,002 & 0,042 \\
\hline $\mathrm{K}^{+}\left(\mathrm{mmol}_{\mathrm{c}} \mathrm{L}^{-1}\right)$ & 0,31 & 69,06 & 0,36 & 60,49 & 0,44 & 66,18 & 0,44 & 38,47 \\
\hline $\mathrm{Na}^{+}\left(\mathrm{mmol}_{\mathrm{c}} \mathrm{L}^{-1}\right)$ & 4,06 & 136,97 & 4,88 & 118,32 & 6,74 & 128,45 & 6,30 & 82,69 \\
\hline $\mathrm{Ca}^{2+}\left(\mathrm{mmol}_{\mathrm{c}} \mathrm{L}^{-1}\right)$ & 1,16 & 11,50 & 1,80 & 12,00 & 4,25 & 12,50 & 4,70 & 5,75 \\
\hline $\mathrm{Mg}^{2+}\left(\mathrm{mmol}_{\mathrm{c}} \mathrm{L}^{-1}\right)$ & 1,97 & 15,00 & 3,00 & 29,00 & 3,06 & 21,00 & 3,41 & 8,50 \\
\hline $\mathrm{Cl}^{-}\left(\mathrm{mmol}_{\mathrm{c}} \mathrm{L}^{-1}\right)$ & 3,00 & 50,00 & 3,40 & 100,00 & 6,40 & 100,00 & 7,00 & 50,00 \\
\hline $\operatorname{RAS}\left(\left(\mathrm{mmol}_{\mathrm{c}} \mathrm{L}^{-1}\right)^{0,5}\right)$ & 3,25 & 37,63 & 3,15 & 26,13 & 3,53 & 31,39 & 3,13 & 30,98 \\
\hline
\end{tabular}

pH - potencial hidrogeniônico; CE - condutividade elétrica; CTe - coliformes termotolerantes; $\mathrm{N}_{\text {total }}$ - nitrogênio total; $\mathrm{P}_{\text {total }}$ - fósforo total; $\mathrm{Fe}$ - ferro; $\mathrm{Mn}$ - manganês; $\mathrm{Cu}$ - cobre; $\mathrm{Zn}$ - zinco; $\mathrm{Pb}$ - chumbo; $\mathrm{Ni}$ - níquel; $\mathrm{Cd}$ - cádmio; $\mathrm{K}^{+}$- potássio; $\mathrm{Na}^{+}$- sódio; $\mathrm{Ca}{ }^{2+}$ cálcio; $\mathrm{Mg}^{2+}$ - magnésio; $\mathrm{Cl}^{-}$- cloreto; e RAS - razão de adsorção de sódio. 
As aplicações do percolado de aterro sanitário foram realizadas a cada dois dias, antes da irrigação com água de abastecimento, de forma a favorecer a lixiviação dos elementos químicos, ao longo do perfil do solo. Durante a aplicação do percolado de aterro sanitário adotaram-se os seguintes procedimentos: a) Mistura do percolado, para homogeneização, evitando-se que sedimentos ficassem retidos no fundo do recipiente; b) Medição da quantidade específica dentro de um balde graduado; c)Transferência da quantidade medida para um regador de 5,0L; e d) Aplicação do percolado com auxílio do regador, diretamente, no solo, dentro de cada parcela experimental.

Para a aplicação da água de abastecimento foi montada uma bancada experimental constituída dos seguintes componentes: a) Um reservatório de concreto com capacidade de armazenamento para $16 \mathrm{~m}^{3}$; b) Um conjunto motobomba centífugo com potência de $0,25 \mathrm{cv}$ : c) um filtro de disco com aberturas de $130 \mu \mathrm{m}$; d) Uma linha principal de tubo de PVC com $24 \mathrm{~m}$ de comprimento e $32 \mathrm{~mm}$ de diâmetro nominal; e) Uma linha de derivação de tubo de PVC com $12 \mathrm{~m}$ de comprimento e $50 \mathrm{~mm}$ de diâmetro nominal; e f) 24 linhas laterais com espaçamento de $0,50 \mathrm{~m}$, dotadas de emissores nãoautocompensantes de $1,6 \mathrm{~L} \mathrm{~h}^{-1}$ de vazão nominal e espaçamento entre emissores de $0,30 \mathrm{~m}$.

O conjunto de irrigação por gotejamento ocupou uma área de $38,44 \mathrm{~m}^{2}$, onde foram delimitadas 25 parcelas experimentais (Figura 1). Cada parcela experimental foi construída nas dimensões de 1,0 x $1,0 \mathrm{~m}\left(1,0 \mathrm{~m}^{2}\right.$ cada $)$, e $0,30 \mathrm{~m}$ entre parcelas, onde foi cultivado o capim elefante (Pennisetum purpureum Schum.). O plantio do capim elefante foi realizado no dia 21 de abril de 2012, coincidindo com o final do período chuvoso do ano de 2012 de forma a minimizar os efeitos de lixiviação do PAS com a água pluvial. Em cada parcela foram plantados nove colmos de capim elefante. As cinco parcelas submetidas ao tratamento $\mathrm{T}_{1}$ (somente água da rede de abastecimento) não receberam nenhuma adubação de fundação, enquanto as demais parcelas receberam apenas o aporte de nutrientes presentes no percolado de aterro sanitário no decorrer do período experimental.

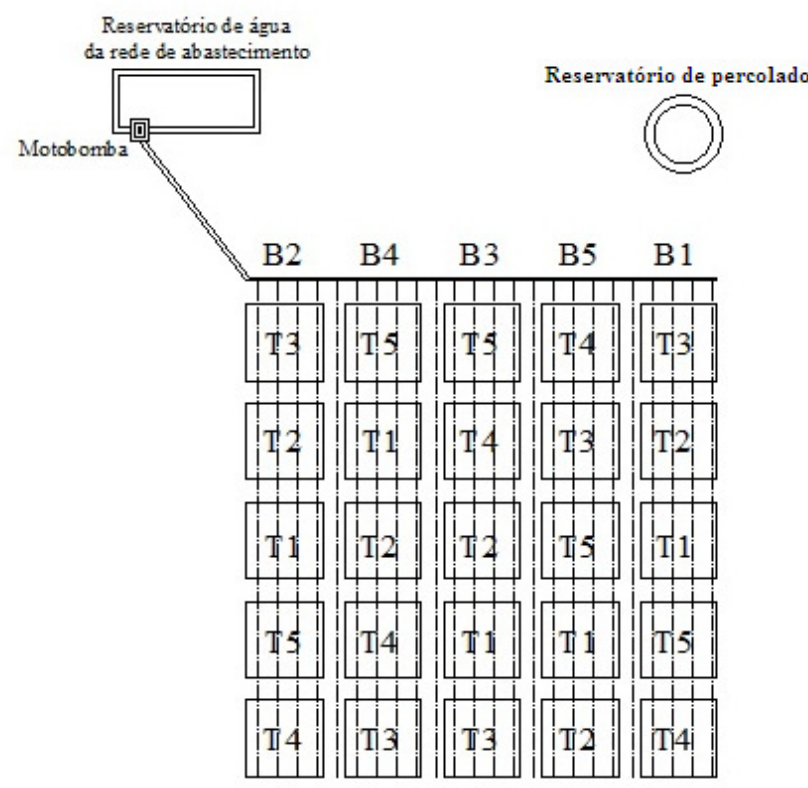

Figura 1. Esquema do delineamento experimental, destacando os blocos (B) e tratamentos (T).

A determinação da necessidade hídrica do capim elefante foi estimada com base na evapotranspiração de referência pela metodologia da FAO, empregando a equação 1 de Penman-Monteith (ALLEN et al., 2006).

$$
\mathrm{ET}_{0}=\frac{0,408 \Delta(\mathrm{Rn}-\mathrm{G})+\gamma \frac{900}{\mathrm{~T}+273} \mathrm{U}_{2}\left(\mathrm{e}_{\mathrm{s}}-\mathrm{e}_{\mathrm{a}}\right)}{\Delta+\gamma\left(1+0,34 \mathrm{U}_{2}\right)}
$$

em que:

ETo - evapotranspiração de referência, em $\mathrm{mm} \mathrm{d}^{-1}$;
$\mathrm{Rn}$ - saldo de radiação à superfície, em $\mathrm{MJ} \mathrm{m}^{-2} \mathrm{~d}^{-1}$;

$\mathrm{G}$ - fluxo de calor no solo, em $\mathrm{MJ} \mathrm{m}^{-2} \mathrm{~d}^{-1}$;

$\mathrm{T}$ - temperatura do ar a $2 \mathrm{~m}$ de altura, em ${ }^{\circ} \mathrm{C}$;

$\mathrm{U}_{2}$ - velocidade do vento à altura de $2 \mathrm{~m}, \mathrm{em} \mathrm{m} \mathrm{s}^{-1}$;

$\mathrm{e}_{\mathrm{s}}$ - pressão de saturação de vapor, em $\mathrm{kPa}$;

$\mathrm{e}_{\mathrm{a}}$ - pressão de vapor atual do ar, em $\mathrm{kPa}$;

$\left(e_{s}-e_{a}\right)$ - déficit de pressão de vapor, em em $\mathrm{kPa}$;

$\Delta$ - declividade da curva de pressão de vapor de saturação, em $\mathrm{kPa}^{\circ} \mathrm{C}^{-1} ; \mathrm{e}$

$\gamma$ - constante psicrométrica, em $\mathrm{kPa}{ }^{\circ} \mathrm{C}^{-1}$. 
Os dados meteorológicos necessários para a estimativa da evapotranspiração de referência (ETo) pela equação de Penman-Monteith como velocidade do vento, umidade relativa do ar, insolação, radiação solar e temperatura foram obtidos de uma estação meteorológica instalada na UFERSA, campus Mossoró/RN.

Para estimar a evapotranspiração da cultura (ETc) utilizaram-se os valores de coeficiente de cultura $(\mathrm{Kc})$ de 0,85 , definido pela FAO para o estágio de desenvolvimento II citado por Lopes et al. (2003).

Os tratamentos utilizados foram: a) $\mathrm{T}_{1}$ Somente água de abastecimento (AA) pela demanda hídrica da cultura; b) $\mathrm{T}_{2}-1 \mathrm{~mm} \mathrm{dia}{ }^{-1}$ de percolado de aterro sanitário (PAS) mais $\mathrm{AA}$; c) $\mathrm{T}_{3}-2 \mathrm{~mm} \mathrm{dia}^{-1}$ de PAS mais AA; $\mathrm{T}_{4}-3 \mathrm{~mm}$ dia $^{-1}$ de PAS mais AA; e $\mathrm{T}_{5}-4 \mathrm{~mm} \mathrm{dia}{ }^{-1}$ de PAS mais AA. As lâminas dos tratamentos utilizadas nos ensaios experimentais estão apresentadas na Tabela 4.

Tabela 4. Lâminas dos tratamentos com dosagens de percolado de aterro sanitário (PAS) mais água de abastecimento (AA), utilizados nos ensaios experimentais.

\begin{tabular}{cccc}
\hline \multirow{2}{*}{ Tratamentos } & \multicolumn{3}{c}{ Lâminas $(\mathbf{m m})$} \\
\cline { 2 - 4 } & PATS & AA & PATS + AA \\
\hline $\mathrm{T}_{1}$ & 0 & 1066,56 & 1066,56 \\
$\mathrm{~T}_{2}$ & 60 & 1066,56 & 1126,56 \\
$\mathrm{~T}_{3}$ & 120 & 1066,56 & 1186,56 \\
$\mathrm{~T}_{4}$ & 180 & 1066,56 & 1246,56 \\
$\mathrm{~T}_{5}$ & 240 & 1066,56 & 1306,56 \\
\hline
\end{tabular}

O PAS foi aplicado somente durante 60 dias, em dias alternados dentro do período experimental de quatro meses, começando após 10 dias do plantio do capim elefante para evitar que o mesmo não germinasse.

Ao final do ciclo do capim elefante em campo, correspondente a 132 dias após o plantio, foram determinadas as características vegetativas altura de planta-AP $(\mathrm{m})$, massa úmida da plantaMUP ( $\left(\mathrm{tha}^{-1}\right)$, massa úmida da folha-MUF $\left(\mathrm{t} \mathrm{ha}^{-1}\right) \mathrm{e}$ massa seca das folhas-MSF $\left(\mathrm{t} \mathrm{ha}^{-1}\right)$, para quantificação da biomassa da gramínea irrigada com PAS.

Determinou-se AP utilizando-se uma mira topográfica (régua) de 4,0 m, verificando-se a distância vertical do nível do solo até o ápice das folhas. Para as demais características, foi determinada uma área útil significativa em cada parcela, com dimensões de $0,50 \times 0,50 \mathrm{~m}\left(0,25 \mathrm{~m}^{2}\right)$, onde foi realizado o corte da cultura para amostragem, seguindo as recomendações de Silva et al. (2010).

No próprio local do experimento foram determinadas MUP e MUF por meio do método gravimétrico, utilizando uma balança de precisão, sendo o resultado expresso em gramas. Em seguida, as amostras foram encaminhadas ao Laboratório de Análises de Solo, Água e Planta (LASAP) da UFERSA para secagem em estufa sob temperatura de $65{ }^{\circ} \mathrm{C}$, durante um período de 72 horas, sendo posteriormente retiradas e pesadas em balança de precisão, determinando-se assim a massa seca das folhas, em gramas.
O experimento foi montado no delineamento em blocos casualizados, com cinco tratamentos (T1, T2, T3, T4 e T5) e cinco repetições, totalizando 25 parcelas experimentais, baseando-se na metodologia proposta por Silva et al. (2010).

Os dados foram submetidos à análise de variância utilizando o teste $\mathrm{F}$ à $5 \%$ de probabilidade. As médias foram comparadas pelo teste de Tukey a $5 \%$ de probabilidade. Na análise estatística utilizouse o programa computacional Sisvar 5.1 Build 72 (FERREIRA, 2011).

\section{RESULTADOS E DISCUSSÃO}

Na Tabela 5 está apresentado um resumo da análise de variância das variáveis massa úmida da planta (MUP), massa úmida da folha (MUF), massa seca da folha (MSF) e altura de planta (AP) do capim elefante irrigado com distintas dosagens de percolado de aterro sanitário (PAS). Notou-se, nessa tabela, que não houve efeito dos tratamentos na alteração das variáveis vegetativas MUP, MUF e MSF do capim elefante, enquanto para a variável AP houve diferença estatística entre as dosagens de PAS. Os valores do coeficiente de variação foram de $36,18,23$ e $9 \%$, sendo classificados como muito alto (>30\%), médio (entre 10 e $20 \%$ ), alto (entre 20 e 30\%) e baixo (<10\%) por Pimentel Gomes (2009) para as variáveis vegetativas MUP, MUF, MSF e $\mathrm{AP}$, respectivamente. 
Tabela 5. Resumo da análise de variância das variáveis massa úmida da planta (MUP), massa úmida da folha (MUF), massa seca da folha (MSF) e altura de planta (AP) do capim elefante irrigado com distintas dosagens de percolado de aterro sanitário (PAS).

\begin{tabular}{cccccc}
\hline \multirow{2}{*}{ Fontes de Variação } & Grau de & \multicolumn{4}{c}{ Quadrado Médio } \\
\cline { 3 - 6 } & Liberdade & MUP & MUF & MSF & AP \\
\hline Blocos & 4 & - & - & - & - \\
Tratamentos & 4 & $12717,50^{\text {n.s. }}$ & $1,38^{\text {n.s. }}$ & $0,17^{\text {n.s. }}$ & $0,26^{*}$ \\
\hline Resíduo & 16 & 22693,51 & 4,92 & 0,60 & 0,06 \\
\hline Coeficiente de variação $(\%)$ & - & 36 & 18 & 23 & 9 \\
\hline
\end{tabular}

Nota: ${ }^{*} \mathrm{e}^{\text {n.s. }}, \mathrm{F}$ significativo e não significativo, respectivamente, a $5 \%$ de probabilidade.

Com base na Figura 2A, evidenciou-se que o tratamento $T_{1}$ foi o que apresentou uma maior quantidade de MUP, correspondente a 455,88 $\mathrm{tha}^{-1}$. Dentre os tratamentos que aplicaram o PAS $\left(\mathrm{T}_{2}, \mathrm{~T}_{3}\right.$, $\mathrm{T}_{4}$ e $\mathrm{T}_{5}$ ), os que apresentaram melhor e pior produtividades de MUP foram $\mathrm{T}_{3}\left(438,40 \mathrm{tha}^{-1}\right) \mathrm{e} \mathrm{T}_{5}$ $\left(328,68 \mathrm{t} \mathrm{ha}^{-1}\right)$, respectivamente, porém, estatisticamente os tratamentos não apresentaram diferenças significativas. Estes resultados diferem muitos dos encontrados por Silva et al. (2001), onde os valores médios de MUP para o capim elefante roxo não irrigado, plantado em covas no espaçamento de $70 \times 80 \mathrm{~cm}$ recebendo calagem e adubação convencional, foram de 21,19 e 13,44 tha 1 no período chuvoso e seco em Areia-PB, respectivamente, sendo os cortes realizados a cada 90 e 60 dias. Os resultados obtidos no presente trabalho, também, foram superiores aos valores de
121,6 e 136 e t ha $^{-1}$ de matéria verde encontrados por Saraiva e Konig (2013) nos estudos com capim elefante roxo, cultivado no município de Pendências/RN mediante irrigação com água residuária doméstica tratada, tendo corte 160 dias após o plantio.

Uma das justificativas encontradas para a menor produtividade de MUP quando aplicadas maiores doses de PAS, deve-se à sodificação do solo causada por esse resíduo líquido, onde as elevadas concentrações de sódio promovem dispersão dos colóides do solo, onde o material disperso constitui um impedimento para a infiltração da água, difusão de gases e emergência das plântulas, além de que a alta concentração de sais no solo é um fator de estresse para as plantas (SILVA et al., 2010).
A

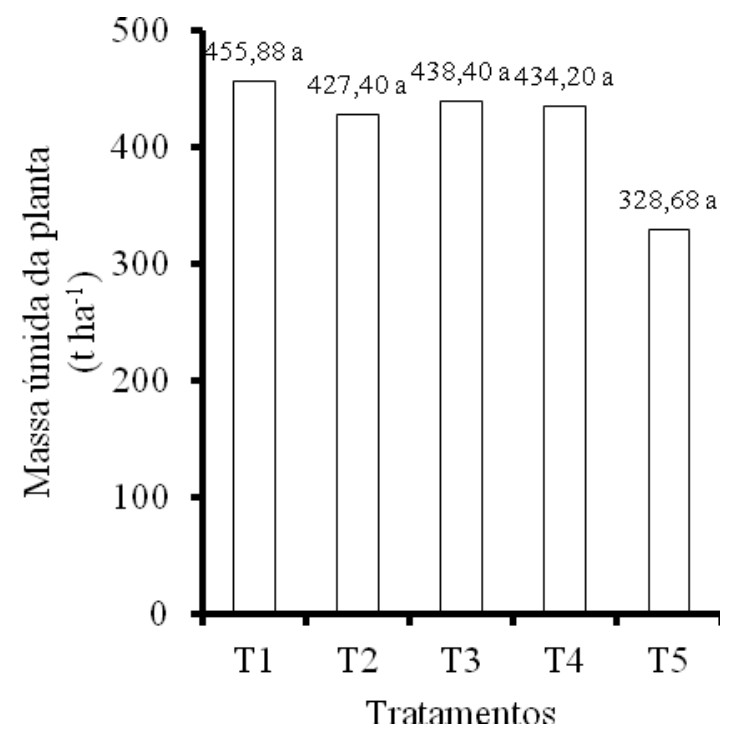

B

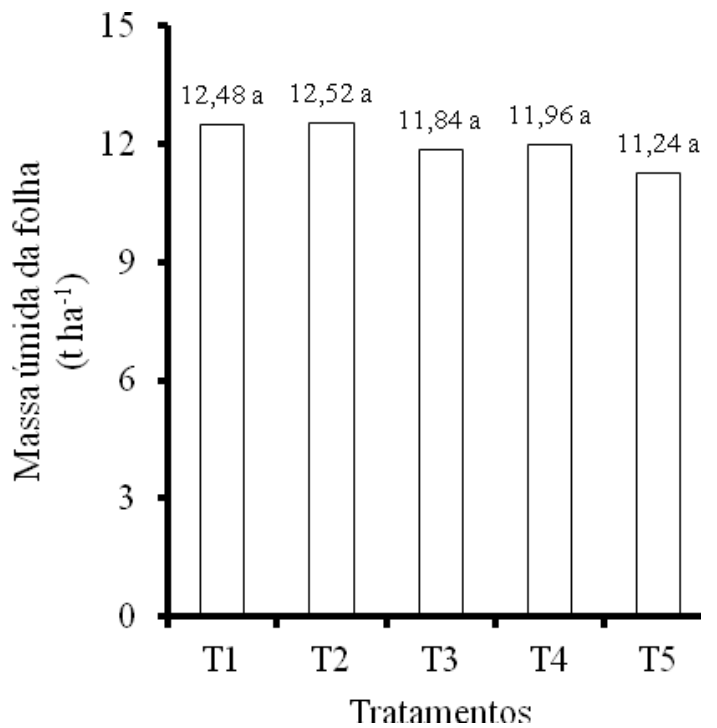

Nota: Médias seguidas de pelo menos uma mesma letra nas colunas para cada tratamento não diferem entre si a $5 \%$ de probabilidade pelo teste de Tukey.

Figura 2. Valores médios da massa úmida da planta-MUP (A) e da massa úmida das folhas-MUF (B) em função dos tratamentos aplicados. 
Um dos sintomas que deve ter sido causado pela sodificação do solo ou toxidez da planta pelo $\mathrm{Na}$, foi de que, após os três meses de plantio, algumas folhas, tanto novas quanto velhas, de alguns tratamentos começaram a ficar enrugadas e deformadas, como pode ser observado na Figura 3.
A

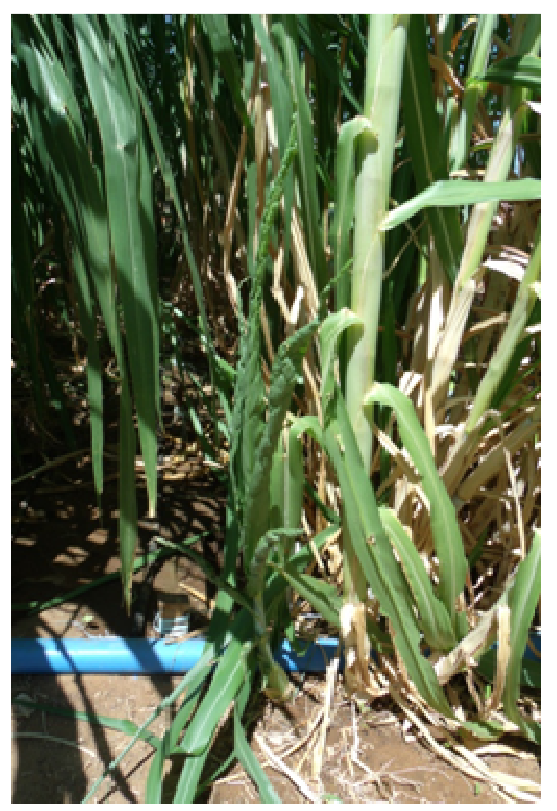

B

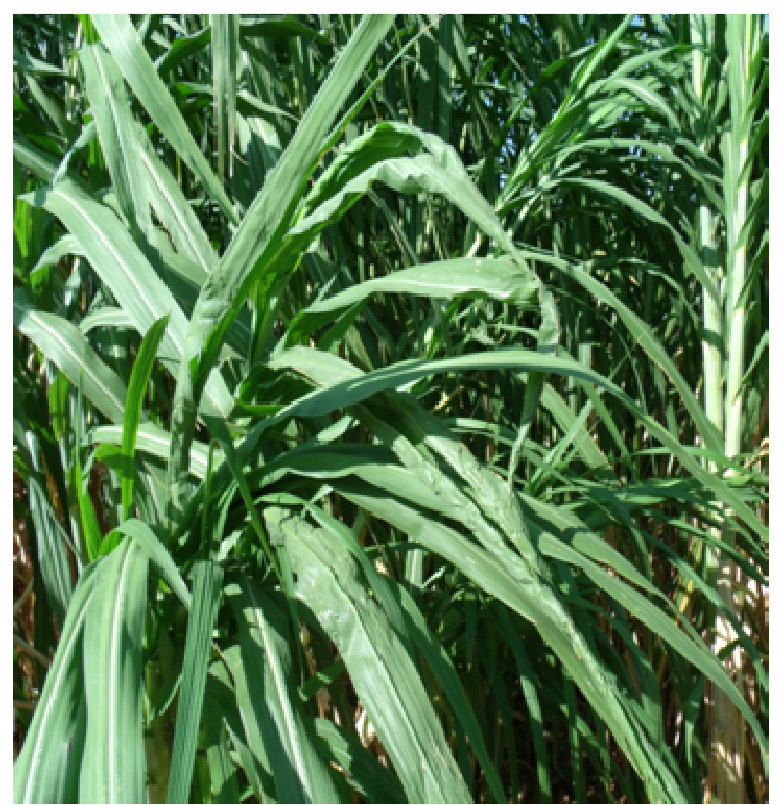

Figura 3. Imagens das alterações morfológicas encontradas nas folhas do capim elefante fertirrigado com distintas dosagens de percolado de aterro sanitário (PAS), após três meses do plantio.

Em relação à massa úmida da folha (MUF), Figura 2B, semelhante à MUP, não houveram diferenças estatísticas significativas com relação aos tratamentos aplicados. Nesse sentido, foi constatado que o tratamento $\mathrm{T}_{2}$ foi o que apresentou maior quantidade de MUF, correspondente a $12,52 \mathrm{t} \mathrm{ha}^{-1}$. Com relação aos demais tratamentos aplicados, não houve diferenças significativas na quantidade de MUF. De acordo com Matos et al. (2008), uma das justificativas encontradas para a menor produtividade de MUP quando aplicadas maiores doses de percolado de resíduo sólido urbano, devese à sodificação do solo causada por esse resíduo líquido, onde as elevadas concentrações de sódio promovem dispersão dos colóides do solo, onde o material disperso constitui um impedimento para a infiltração da água, difusão de gases e emergência das plântulas, além de que a alta concentração de sais no solo é um fator de estresse para as plantas.

Como pode ser observado na Figura 4A, o tratamento $\mathrm{T}_{1}$ (somente água da rede de abastecimento) foi o que apresentou uma maior quantidade de MSF, correspondente a 3,64t ha- . Com relação aos tratamentos que aplicaram PAS $\left(\mathrm{T}_{2}, \mathrm{~T}_{3}, \mathrm{~T}_{4}\right.$ e $\left.\mathrm{T}_{5}\right)$, os tratamentos $\mathrm{T}_{2}\left(3,56 \mathrm{tha}^{-1}\right)$ e $\mathrm{T}_{5}$ $\left(3,16 \mathrm{t} \quad \mathrm{ha}^{-1}\right)$ não apresentaram diferenças significativas, corroborando com Cabral et al. (2011) que, também, não obtiveram efeito significativo das doses de água residuária de suinocultura em relação a produção de matéria seca de capim elefante. Os resultados do presente trabalho diferem dos encontrados por Matos et al. (2013), que evidenciaram aumento significativo na produtividade da matéria seca da parte aérea do capim-Tifton $85 \mathrm{com}$ as taxas de aplicação do percolado de resíduo sólido urbano, sendo encontrada produtividade acumulada de matéria seca (dois cortes) de até $15 \mathrm{t} \mathrm{ha}^{-1}$, obtida aos 45 dias de cultivo.

Na literatura as informações sobre os efeitos de PAS na produção de matéria seca do capim elefante são escassas, no entanto existem resultados tipos de água residuárias. Como no trabalho de Friderichs et al. (2010), que avaliaram a produção de capim elefante em Vertissolo sob diferentes doses de efluentes produzidos em fossa séptica biodigestora; onde verificaram que houve maior produção de matéria seca do capim-elefante nas duas épocas avaliadas, porém os resultados indicaram que o uso contínuo das duas maiores doses de efluentes resultou em menor desenvolvimento de folhas em relação às hastes. Em outro estudo, Drumond et al. (2006) analisaram a produção de matéria seca em pastagem de capim Tifton 85 irrigada com diferentes doses de dejeto líquido suíno; verificaram que houve um efeito significativo das doses em relação à produção de matéria seca pré-pastejo, ocorrendo acréscimos de 
produção com o aumento das doses, onde um fornecimento de $200 \mathrm{~m}^{3} \mathrm{ha}^{-1} \mathrm{ano}^{-1}$ de dejeto líquido suíno, possibilitou a produção de 6,0 toneladas de matéria seca da forrageira por ciclo de 28 dias.

Observou-se na Figura 4B que o tratamento $\mathrm{T}_{2}$ foi $\mathrm{o}$ que apresentou uma maior $\mathrm{AP}$, correspondente a $2,86 \mathrm{~m}$; em geral os valores de AP do capim elefante deste estudo foram menores aos encontrados por Dall'agnol et al. (2004), que registraram valor médio de $3 \mathrm{~m}$ de altura, 126 dias após o plantio. $\mathrm{O}$ tratamento $\mathrm{T}_{2}$ não diferiu estatisticamente dos tratamentos $\mathrm{T}_{1}$ e $\mathrm{T}_{3}$, onde este último, também, não diferiu estatisticamente dos tratamentos $\mathrm{T}_{4}$ e $\mathrm{T}_{5}$. Estes resultados diferem dos obtidos por Cabral et al. (2011), onde não houve efeito significativo das doses de água residuária de suinocultura em relação à altura das plantas. No entanto, os resultados do presente estudo foram semelhantes aos encontrados por Saraiva e Konig
COELHO, D. C. L. et al.

(2013) com capim elefante roxo irrigado com água residuária doméstica tratada, onde o valor médio de AP foi de 2,82 m, 160 dias após o plantio. Destacase ainda que, à medida que se aumentaram as doses de PAS aplicadas no solo, ocorreu uma diminuição na quantidade da MSF, mostrando que doses elevadas desse resíduo líquido prejudicam a produção de MSF.

Semelhante ao que ocorreu nas variáveis MUP, MUF e MSF, o tratamento $\mathrm{T}_{5}$ apresentou uma menor AP, mostrando que quanto maior a quantidade de percolado de RSU aplicado no solo, menor será o desenvolvimento das características vegetativas do capim elefante. Uma das justificativas para esse fato poderia ser o processo de sodificação do solo atribuído a elevadas concentrações do percolado de RSU, causando a indisponibilidade de água para a cultura.
A

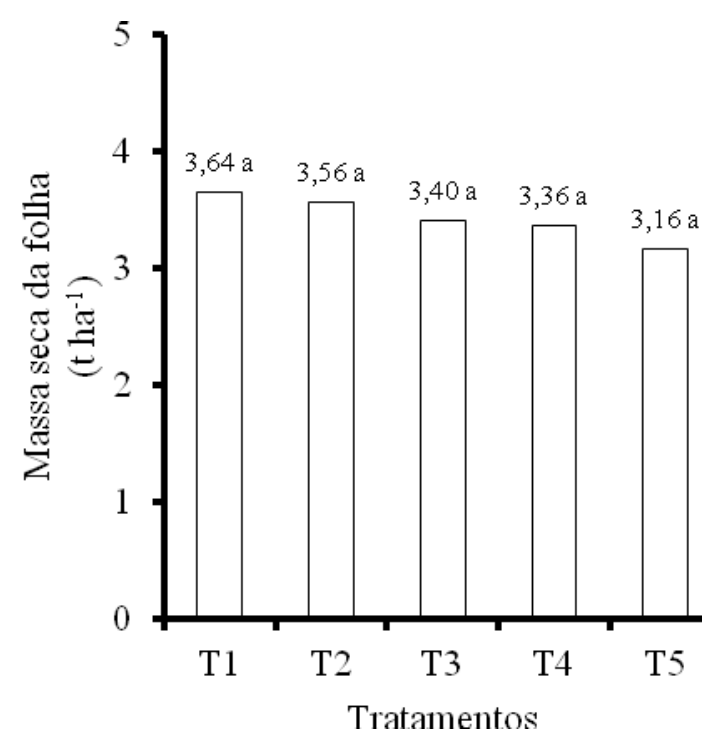

B

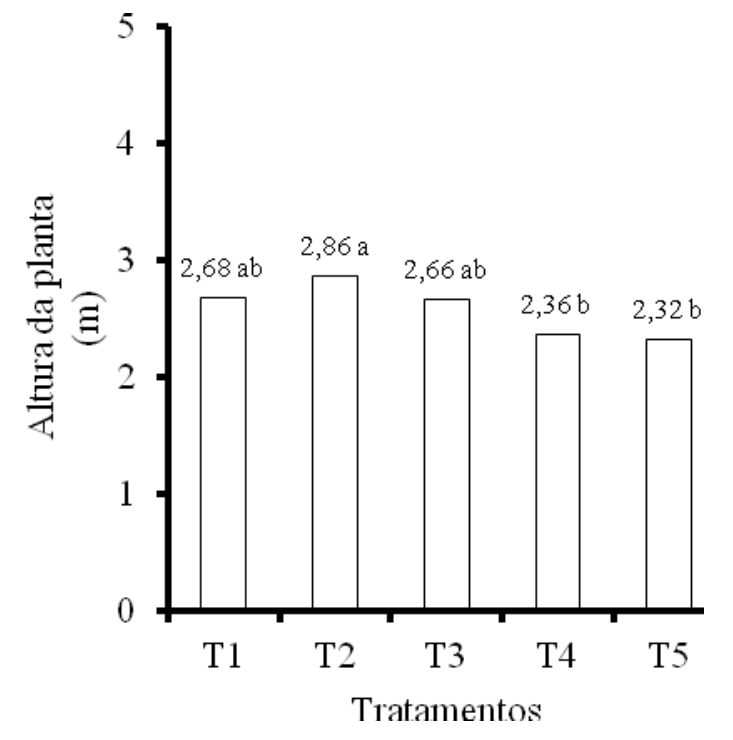

Nota: Médias seguidas de pelo menos uma mesma letra nas colunas para cada tratamento não diferem entre si a $5 \%$ de probabilidade pelo teste de Tukey.

Figura 4. Valores médios de massa seca da folha-MSF (A) e altura da planta-AP (B) em função dos tratamentos aplicados.

Além disto, contatou-se que o PAS utilizado no experimento é um subproduto de interesse agronômico e que apresenta características essenciais para uso no cultivo agrícola, podendo assim, ser utilizado na fertirrigação de cultivos para fins energéticos, promovendo tanto um destino viável a este resíduo líquido quanto vantagens de redução de custo com fertilizantes, tomando-se cuidado apenas com a dose aplicada, ao tipo de solo e profundidade do lençol freático.
A recirculação do percolado de aterro nas células do aterro sanitário, aliada a produção de capim elefante favorece tanto uma destinação final e tratamento viável para esse resíduo líquido, retirando alguns elementos contaminantes, quanto à produção de briquetes para fins energéticos a partir de biomassa vegetal dessa cultura para substituição da madeira, retirada do Bioma Caatinga, em fábricas de material cerâmico e padarias do semiárido. 


\section{CONCLUSÕES}

Não houve diferença estatística entre os tratamentos para as variáveis vegetativas do capim elefante massa úmida da planta, massa úmida da folha e massa seca da folha.

Para a variável vegetativa altura de planta houve diferença estatística entre os tratamentos T2 ( $1 \mathrm{~mm} \mathrm{~d}^{-1}$ de percolado mais água de abastecimento), T4 $\left(3 \mathrm{~mm} \mathrm{~d}^{-1}\right.$ de percolado mais água de abastecimento) e $\mathrm{T} 5\left(4 \mathrm{~mm} \mathrm{~d}^{-1}\right.$ de percolado mais água de abastecimento).

$\mathrm{O}$ tratamento $\mathrm{T} 2\left(1 \mathrm{~mm} \mathrm{~d}^{-1}\right.$ de percolado mais água de abastecimento) apresentou melhor
COELHO, D. C. L. et al.

resultado com relação às características vegetativas do capim elefante, e que, elevadas concentrações de percolado aplicadas no solo causam redução na sua qualidade, e consequentemente, na produção de biomassa dessa cultura.

\section{AGRADECIMENTOS}

À Universidade Federal Rural do SemiÁrido (UFERSA) e Conselho Nacional de Desenvolvimento Científico e Tecnológico (CNPq) pela possibilidade de realização desse trabalho, através do apoio financeiro e material, e infraestrutura concedida.

\begin{abstract}
The use of landfill leachate (PAS) in the production of biomass for energy is an alternative that minimizes environmental degradation. This study aimed to analyze the effect of different doses of PAS in elephant grass production (Pennisetum purpureum Schum.). For this, the experiment was set up in a randomized block design with five treatments (T1 - only water supply - AA, T2 - $1 \mathrm{~mm} \mathrm{day}^{-1}$ of PAS more AA, T3 - 2 mm day ${ }^{-1}$ of PAS more AA, T4 - $3 \mathrm{~mm}$ $\mathrm{day}^{-1}$ of PAS more AA and T5 $-4 \mathrm{~mm} \mathrm{day}^{-1}$ of PAS more AA) and five repetitions, totaling 25 experimental plots. The elephant grass was cultivated in ultisol during 132 days in Mossoró/RN. At the end of elephant grass cycle were determined vegetative characteristics plant height (PH), plant fresh weight (MUP), leaf fresh weight (MUF) and leaf dry weight (MSF). It was shown to MUP, MUF and MSF that there was no statistical difference between the treatments, however, to AP, T2 treatment the highest values $(2.86 \mathrm{~m})$, differing of the treatments T4 and T5. In general, treatment T2 showed a better performance with respect to elephant grass vegetative characteristics.
\end{abstract}

KEYWORDS: Leachate. Fertigation. Biomass.

\title{
REFERÊNCIAS
}

ALLEN, Richard; SANTOS PEREIRA, Luis Alberto; RAES, Dirk; SMITH, Martin. Evapotranspiracíon del cultivo, Guías para la determinación de los requerimientos de agua de los cultivos. Roma: FAO, 2006. 298 p.

ALSAMAWI, A. A.; ZBOON, A. R. T.; ALNAKEEB, A. Estimation of baghdad municipal solid waste generation rate. Engineering \& Technology Journal, Baghdad, v. 27, n. 1, p. 1-15, 2009.

CABRAL, J. R.; FREITAS, P. S. L.; REZENDE, R.; MUNIZ, A. S.; BERTONHA, A. Impacto da água residuária de suinocultura no solo e na produção de capim-elefante. Revista Brasileira de Engenharia Agrícola e Ambiental. Campina Grande, v. 15, n. 8, p. 823-831, ago., 2011.

CARMO FILHO, Francisco de; OLIVEIRA, Odaci Fernandes de. Mossoró: Um município do semi-árido nordestino, caracterização climática e aspecto florístico. Mossoró: ESAM, 1995. 62p. (Coleção Mossoroense, série B).

CARVALHO, A. L.; MATOS, A. T. DE; HAMAKAWA, P. J.; AZEVEDO R. F. Produção de percolado por resíduos sólidos urbanos de diferentes idades, na presença de resíduos da construção civil e sob recirculação.

Engenharia na Agricultura, Viçosa, v. 14, n. 2, p. 131-138, abr.-jun., 2006.

DALL'AGNOL, M.; SCHEFFER-BASSO, S. M.; NASCIMENTO, J. A. L.; SILVEIRA, C. A. M.; FISCHER, R. G. Produção de forragem de capim elefante sob clima frio: curva de crescimento e valor nutritivo. Revista Brasileira de Zootecnia, Viçosa, v. 33, n. 5, p. 1110-1117, set.-oct., 2004. 
DRUMOND, L. C. D.; ZANINI, J. R.; AGUIAR, A. P. A.; RODRIGUES, G. P.; FERNANDES, A. L. T. Produção de matéria seca em pastagens de Tifton 85 irrigada, com diferentes doses de dejeto líquido de suíno. Engenharia Agrícola, Jaboticabal, v. 26, n. 2, p. 426-433, mai-ago., 2006.

EMPRESA BRASILEIRA DE PESQUISA AGROPECUÁRIA - EMBRAPA. Sistema Brasileiro de Classificação de Solos. 2. ed. Rio de Janeiro: EMBRAPA, 2006. 412p.

FERREIRA, D. F. Sisvar: a computer statistical analysis system. Ciência e Agrotecnologia (UFLA), Lavras, v. 35, n. 6, p. 1039-1042, nov.-dec., 2011.

FRIDERICHS, B. A.; ABREU, F.; TOMICH, T. R.; FEIDEN, A.; GALVANI, F.; LISITA, F. O.; SILVA, W. T. L.; CORREAA, M.; DIAMANTE, M.; SOARES, M. T. S. Produção de capim elefante em vertissolo sob diferentes doses de efluentes de fossa séptica biodigestor. Cadernos de Agroecologia, Corumbá, v. 5, n. 1, p. 1-4, jan.-dez., 2010.

LOPES, R. S.; FONSECA, D. M.; OLIVEIRA, R. A.; NASCIMENTO JÚNIOR, D.; ANDRADE, A. C.; STOCK, L. A.; MARTINS, C. E. Disponibilidade de matéria seca em pastagens de capim-elefante irrigadas. Ciência Agrotecnológica, Lavras, v. 27, n. 6, p. 1388-1394, nov.-dez., 2003.

MATOS, A. T.; CARVALHO, A. L.; AZEVEDO, I. C. D. d'A. Viabilidade do aproveitamento agrícola de percolados de resíduos sólidos urbanos, Revista Brasileira de Engenharia Agrícola e Ambiental. Campina Grande, v. 12, n. 4, p. 435-440, jul.-ago., 2008.

MATOS, A. T.; SILVA, D. F.; LO MONACO, P. A. V.; PEREIRA, O. G. Produtividade e composição química do capim-Tifton 85 submetido a diferentes taxas de aplicação do percolado de resíduo sólido urbano.

Engenharia Agrícola, Jaboticabal, v. 33, n. 1, p. 188-200, jan.-fev., 2013.

PIMENTEL GOMES, Frederico. Curso de estatística experimental. 15. ed. Piracicaba: FEALQ, 2009. 451 p.

RAMOS E PAULA, L. E.; TRUGILHO, P. F.; REZENDE, R. N.; ASSIS, C. O.; BALIZA, A. E. R. Produção e avaliação de briquetes de resíduos lignocelulósicos. Pesquisa Florestal Brasileira, Colombo, v. 31, n. 66, p. 103-112, abr.-jun., 2011. http://dx.doi.org/10.4336/2011.pfb.31.66.103

RICE, Eugene; BAIRD, Rodger; EATON, Andrew; CLESCERI, Lenori (Eds) Standard methods for the examination of water and wastewater. 22. ed. Washington: APHA, AWWA, WPCR, 2012. 1496p.

SANTOS, Renato Lemos dos. Capim elefante cultivado em solo ácido com aplicação de gesso como alternativa fitoenergética para o pólo gesseiro do Araripe/PE. 2011 . 105 f. Dissertação (Mestrado em Ciência do Solo) - Curso de Pós-Graduação em Ciência do Solo, Universidade Federal Rural de Pernambuco, Recife, 2011.

SANTOS, E. A.; SILVA, D. S.; QUEIROZ FILHO, J. L. Aspectos produtivos do capim-elefante (Pennisetum purpureum, Schum.) cv. Roxo no brejo paraibano. Revista Brasileira de Zootecnia, Viçosa, v. 30, n. 1, p. 3136, fev., 2001.

SANTOS, M. C. L.; GONÇALVES-DIAS, S. L. F. Resíduos sólidos urbanos e seus impactos sócio ambientais. São Paulo: IEE-USP, 2012. 80p.

SARAIVA, V. M.; KONIG, A. Produtividade do capim-elefante-roxo irrigado com efluente doméstico tratado no semiárido potiguar e suas utilidades. HOLOS, Natal, v. 29, n. 1, p. 28-46, jan.-fev., 2013.

http://dx.doi.org/10.15628/holos.2013.1251

SCHÜTZ, F. C. A.; ANAMI, M. H.; TRAVESSINI, R. Desenvolvimento e ensaio de briquetes fabricados a partir de resíduos lignocelulósicos da agroindústria. Inovação e Tecnologia, Medianeira, v. 1, n. 1, p. 1-8, jan.dez., 2010. 
SILVA, D. F., MATOS, A. T.; PEREIRA, O. G.; CECON, P. R.; MOREIRA, D. A. Disponibilidade de sódio em solo com capim tifton e aplicação de percolado de resíduo sólido. Revista Brasileira de Engenharia Agrícola e Ambiental, Campina Grande, v. 14, n. 10, p. 1094-1100, out., 2010.

http://dx.doi.org/10.1590/S1415-43662010001000011

SILVA, D. F.; MATOS, A. T.; PEREIRA, O. G.; CECON, P. R.; BATISTA, R. O.; MOREIRA, D. A. Alteração química de solo cultivado com capim Tifton 85 (Cynodon spp.) e fertirrigado com percolado de resíduo sólido urbano. Acta Scientiarum. Technology. Maringá, v. 33, n. 3, p. 243-251, jul.-set., 2011.

SILVA, Fábio César da. Manual de análises químicas de solos, plantas e fertilizantes. 2.ed. Brasília: Embrapa Informação Tecnológica, 2009. 627p. 